\title{
Green Product Design Based on the Concept of Sustainable Development
}

\author{
Zhang Shenglin \\ Academy of Arts, Guilin University of Technology, Guilin 541006, Guangxi \\ Corresponding author Email: 945352942@qq.com
}

Keywords: Sustainable development; Green product; Application method; Design method

Abstract: The continuous development of human society has brought all kinds of ecological environment problems. The design of green product, which is integrated into the concept of sustainable development, is the inevitable product of the development of human society. This paper mainly introduces the concept of green product design, the application of design and the design method to the readers.

\section{Overview of Green Design}

The green design extends from product manufacturing to product packaging, product promotion and product marketing, which are closely related to product manufacturing, and further extends to the consciousness of the green service and green culture in the whole society ${ }^{[1]}$. One of the main features of green design is to consider the life cycle of the design of the product, and another feature is to save the resources and protect the environment fundamentally when the function of the product is ensured. Nowadays, the theme of green product design is mainly the embodiment of the harmonious development of human, nature and society in the design and production of the products.

Green design is to fix what's broken in the design of traditional industrial. From the whole life cycle of the design production to the use of waste to recycle, an idea should be infiltrated, that is to permeate the concept of sustainable development. In real life production, this design integrates series of new technologies and embodies the value of sustainable development. The design of green product must choose material and technology according to environmental protection index, and reduce energy consumption in the process of production, then meet the requirements of product recycling, also integrate the thoughts of sustainable development in every link, together with realizing the optimization of resources, environment and labor protection.

\section{The Requirements of the Concept of Sustainable Development for Product Design}

\subsection{Formulate design plan for sustainable development and industrial chain}

The development of human society has led to the continuous reduction of the resources on the earth. With the continuous development of the economy, the environmental protection and development of green energy as well as the use of green materials has become the mainstream thought. Also the customers have taken sustainability as the top standard for choosing products. This 
is a new market opportunity, which has created new fields and opportunities for product design. Therefore, making the sustainable design be prerequisite for the innovation of the product design is the key to perfect the industrial chain. At the same time, the design of the product is a long and challenging task too.

\subsection{Pay attention to the development of sustainable design and increase the additional value of products}

The development of products occupies an important position in the industrial chain, and its additional value can not be ignored. In order to promote the common development of production, consumption and environment, the "Win-win" situation should be set up. First of all, the raw materials to be produced should be made of renewable materials, and on the basis of meeting the market demand, the cost is reduced and the environmental pressure is reduced by simplifying the production industry. Secondly, product transportation should choose recycling packaging materials to reduce transportation pressure, and guarantee the integrity of products also save transportation space, then increase the additional value of products, together with using colors that are closer to the natural and low price environmental protection materials which are more attractive to consumers.

\subsection{Emphasize the position of the designer's main body of innovation}

The design of green products requires continuous exploration of design technology and design elements. With the development and popularization of virtual reality technology and augmented reality technology, the enterprise would continue to advance with the concept of sustainable development, and the main position of the designer's innovation could be shown ${ }^{[2]}$. The designer plays a decisive role in applying the existing technology to the design of green products. At the same time, it is also the promoter to reduce the cost and improve the production efficiency. The enterprise should also actively accept the fresh blood and enhance the competitiveness of the enterprise.

\section{The Design Methods of Green Product of Sustainable Development Concept}

\subsection{Design method of folding}

The biggest advantage of the design method of folding is that it can save space and it is the embodiment of energy saving in green product design. This principle has been reflected in ancient China, such as the folding fan used by the ancients, which greatly reduced the space and provided convenience for the people to carry. In the north, the "folding stool" is more convenient to carry and it is more stable when it is unfold. This is the principle of using the shaft folding. Parallel folding can also reduce volume or area, such as screens. When folded, they can be easily transported, and then they can cover up and beautify the environment. Combining the above examples, it is obvious that this design method should follow the following principles, the first one is to improve the utilization of space, the second one is to carry transportation, the third one is about the diversity of the product, and the forth one is about safety and comfort. In order to achieve the above points, designers need to carry out organic treatments and multiple tests in the design to ensure the performance of the products.

\subsection{Microfilm design method}

The miniaturized design method is also a space saving design method, while the folding method has bigger advantage of reducing consumables. This method is mostly applied in the electronic field, which improves the convenience of products and meets the concept of sustainable development. In 
the concrete implementation, we should pay attention to as followed, firstly, the designers can't chose for the advantages which help saving material and space and ignore the use function and value of the product that come with it. It should reduce the volume reasonably in the case of guaranteeing the basic function of the product so as to make it easy to use and carry. Secondly, the structure of the product should be rationally transformed, and the miniature design changes the original structure of the product, which is contrary to the habit of people using for a long time. Therefore, designers should give full consideration to people's daily habits and minimize the inconvenience caused by changes in product structure. Thirdly, we should pay attention to the interaction between the people and the products, especially for the electronic products, in the micro design, while trying to improve the intersex of the products and make the users get a pleasant experience in the new product as much as possible, which shows the simple but great effect of the miniature design. In the application of microfilm design, the product structure should be changed rationally on the basis of ensuring the function and usability of the product, so the designer should consider both the function of the product and the reasonable choice of material to realize the reasonable miniature.

\subsection{Module design method}

Modular design has a wide range of applications in industrial product design. The advantage of this method is that it can effectively shorten the design and manufacturing process of the product and reduce the cost. This method is mainly implemented in the current design, and the first and serialized design is to meet the needs of the product by assembling and deforming to achieve the purpose of product function. Secondly, modular design is achieved through the combination of direct combination and indirect combination. Multiple links and combinations of modules through media, such as a simple plastic wardrobe, are linked to all small squares, which effectively save the cost of production and assembly. If you can't link directly, use a link device to get the combinational effect. Thirdly, maintain the coordination of the appearance of the product. Because the product is formed by combination, it is easy to make people feel trivial in the vision, the designer should take the color decoration technology into consideration in many aspects to ensure the overall effect of the product. In this design, the designers need to find a balance that can not only satisfy the modularizational effect but also satisfy the needs of consumers. Modular design saves resources and extends the life cycle of products.

\section{Conclusion}

To bring convenience to people's life, work and entertainment are the essence of product design. But in design, if it is against the natural ecological environment on which human beings are born, it will outweigh the gains and put the cart before the horse. Therefore, the designers for the new product must establish the concept of sustainable development in the design, on the one hand to meet the consumer experience, on the other hand, to reflect the concept of environmental protection, and show the sense of social responsibility of the design, also cause the sustainable development of consumers to resonate. We believe that under the joint efforts of everyone, there would be a continuous production of green products, and become a beautiful landscape line in contemporary product design, contributing to the protection of natural ecological environment and the sustainable development of human design.

\section{References}

[1] Liu Lin. The significance of integrating the green concept of humanized thinking into product design [J]. Art and 
Technology, 2014,27 (12): 129+110+121.

[2] Sun Hui. Application of sustainable development concept in contemporary product design [J]. Art Evaluation, 2016 (08): 16-17.

[3] Ma Yuan. On the application of the concept of sustainable development in product design [J]. Journal of Anhui University of Technology (SOCIAL SCIENCE EDITION), 2016,33 (03): 11-12.

[4] Zhang Wei. Application of green design concept in product packaging design [J]. Arts and Technology, 2017,30 (12): 290.

[5] Chou Li. Green marketing -- the inevitable choice for domestic enterprises to achieve sustainable development [J]. Journal of Shandong Normal University (HUMANITIES AND SOCIAL SCIENCES), 2012,57 (02): 94-102.

[6] Zhang Xuemei, Chen Gang, Feng Shuai. Green product design strategies participated by the government, [J]. Systems Engineering, 2014,32 (06): 126-131. 